\title{
Development and growth of the pelvic fin in the extant coelacanth Latimeria chalumnae
}

Mansuit Rohan ${ }^{1,2}$; Clément Gaël${ }^{1}$; Herrel Anthony²; Dutel Hugo ${ }^{3,4}$; Tafforeau Paul5; Santin Mathieu D. ${ }^{6}$; Herbin Marc ${ }^{2}$

1 UMR 7207 Centre de Recherche en Paléontologie, Paris, MNHN - Sorbonne Université - CNRS, Département Origines \& Evolution, 57 rue Cuvier, 75005 Paris, France

2 UMR 7179 MECADEV, MNHN - CNRS, Département Adaptations du Vivant, 57 rue Cuvier, 75005 Paris, France

${ }^{3}$ School of Earth Sciences, University of Bristol, Bristol, UK

${ }^{4}$ School of Engineering and Computer Science, University of Hull, Hull, UK

${ }^{5}$ European Synchrotron Radiation Facility, 71 avenue des Martyrs, cs-40220, 38043 Grenoble Cedex, France

${ }^{6}$ Inserm U 1127, CNRS UMR 7225, Centre for Neurolmaging Research, ICM (Brain \& Spine Institute), Sorbonne University, Paris, France

\section{Address for correspondence:}

Rohan Mansuit

UMR 7179 MECADEV, MNHN - CNRS,

Département Adaptations du Vivant

55 rue Buffon

75005 Paris, France

e-mail : rohan.mansuit@mnhn.fr

Running title: Ontogeny of the pelvic appendage of Latimeria

\section{Grant information:}

This article has been accepted for publication and undergone full peer review but has not been through the copyediting, typesetting, pagination and proofreading process which may lead to differences between this version and the Version of Record. Please cite this article as doi: 10.1002/ar.24452 
Grant sponsor: Agence Nationale de la Recherche in the LabEx ANR-10-LABX-0003-BCDiv Grant number: program 'Investissements d'avenir' n ANR-11-IDEX-0004-02 


\begin{abstract}
The ontogeny of the paired appendages has been extensively studied in lungfishes and tetrapods, but remains poorly known in coelacanths. Recent work has shed light on the anatomy and development of the pectoral fin in Latimeria chalumnae. Yet, information on the development of the pelvic fin and girdle is still lacking. Here, we described the development of the pelvic fin and girdle in Latimeria chalumnae based on 3D reconstructions generated from conventional and X-ray synchrotron microtomography, as well as MRI acquisitions. As in other jawed vertebrates, the development of the pelvic fin occurs later than that of the pectoral fin in Latimeria. Many elements of the endoskeleton are not yet formed at the earliest stage sampled. The four mesomeres are already formed in the fetus, but only the most proximal radial elements (pre-axial radial 0-1) are formed and individualized at this stage. We suggest that all the preaxial radial elements in the pelvic and pectoral fin of Latimeria are formed through the fragmentation of the mesomeres. We document the progressive ossification of the pelvic girdle, and the presence of a trabecular system in the adult. This trabecular system likely reinforces the cartilaginous girdle to resist the muscle forces exerted during locomotion. Finally, the presence of a pre-axial element in contact with the pelvic girdle from the earliest stage of development onwards questions the mono-basal condition of the pelvic fin in Latimeria. However, the particular shape of the mesomeres may explain the presence of this element in contact with the girdle.
\end{abstract}

\title{
Keywords
}

Actinistia, sarcopterygians, ontogeny, appendages, endoskeleton 


\section{Introduction:}

Among sarcopterygians, the living coelacanths Latimeria chalumnae (Smith, 1939) and L. menadoensis (Pouyaud et al., 1999) are the only living representatives of the Actinistia, a clade closely related to lungfishes and tetrapods (Forey, 1998; Friedman et al., 2007; Clack, 2012; Amemiya et al., 2013). Although the anatomy of Latimeria chalumnae is well known (Millot and Anthony, 1958, 1965; Millot et al., 1978), its development remains largely unknown. Indeed, only a few embryos and one juvenile are present in collections worldwide (Nulens et al., 2011). Due to the improvement of non-invasive imaging techniques such as conventional and synchrotron micro-tomography, as well as magnetic resonance imaging, it is now possible to study the development of small and complex internal structures of the coelacanth like the lung (Cupello et al., 2015), the neurocranium (Dutel et al., 2019) and the pectoral fin (Mansuit et al., 2019).

The endoskeleton elements of the paired fins or limbs are organized along a single metapterygial axis in sarcopterygians (Millot and Anthony, 1958; Shubin and Alberch, 1986). However, whereas the development of paired appendages in lungfishes and tetrapods is relatively well known (Shubin and Alberch, 1986; Boisvert et al., 2013; Jude et al., 2014), it remains poorly studied in coelacanths (but see (Mansuit et al., 2019). Yet, the development of the pelvic appendages of vertebrates occurs later than the pectoral appendages (Cubbage and Mabee, 1996; Mabee and Trendler, 1996; Mabee and Noordsy, 2004). Therefore, documenting of the development of the pelvic fin of Latimeria is important to fully understand the development of the paired fins in this species. Following our recent work on pectoral fin development (Mansuit et al., 2019), we here describe the anatomy and development of the pelvic appendage of Latimeria based on an ontogenetic series of five different stages.

\section{Materials and methods:}

\section{Specimens}

The developmental series includes five stages including specimens from several Museum collections (Fig. 1). The first stage is a fetus of $5 \mathrm{~cm}$ total length (TL) (international number: CCC 202.1) found inside the 
female specimen CCC 202 captured off the coast of Tanzania in 2005 and conserved in the collection of the South African Institute for Aquatic Biodiversity (SAIAB) in Grahamstown (collection number: SAIAB 76199). The stage two is a pup with yolk sac of $32.3 \mathrm{~cm}$ TL (CCC 29.5) found inside the female specimen CCC 29 captured in the Comores in 1969 and conserved in the collection of the Muséum national d'Histoire naturelle (MNHN), Paris (collection number: MNHN AC 2012-22). The stage three is a late pup without yolk sac of $34.8 \mathrm{~cm}$ TL (CCC 162.21) found inside the female CCC 162 captured off the coast of Mozambique in 1991 and conserved in the collections of the Zoologische Staatssammlung of Munich (collection number: ZSM 28409). The stage four is a juvenile of $42.5 \mathrm{~cm}$ TL (CCC 94) captured off the coast of Grande Comore Island in 1974 and conserved in the collections of the MNHN, Paris (collection number: MNHN AC 2012-27). Imaging reconstructions and observations on adult stage (stage 5) were mainly based on a male specimen of $132 \mathrm{~cm}$ TL (CCC 27) captured off the coast of Grande Comore Island in 1961 and conserved in the collections of the MNHN, Paris (collection number: MNHN AC 2012-21) (Nulens et al., 2011). Direct anatomical observations were also made from on a dissected and prepared pelvic fin skeleton of adult specimen CCC 7 (collection number: MNHN AC 2012-5). All specimens of the MNHN, Paris are conserved in a 6-7\% formaldehyde solution, while the others are preserved in an aquaeous ethanol solution (70\%).

Imaging

Figure 2 illustrates sections through the girdle and fins of the different specimens illustrating the quality of the raw data used in this paper.

Stage 1 - Fetus (CCC 202.1)

The specimen was scanned using long propagation phase-contrast synchrotron X-ray microtomography at the ID19 beamline of the European Synchrotron Radiation Facility (ESRF), Grenoble (France). It was imaged in a glass cylinder filled with ethanol, at a voxel size of $6.5 \mu \mathrm{m}$, with a high-quality pink beam using the ID19 W150 wiggler and a gap of $50 \mathrm{~mm}$ filtered by $2 \mathrm{~mm}$ of aluminium, $0.25 \mathrm{~mm}$ of copper and 0.2 $\mathrm{mm}$ of gold. The scintillator was a $250-\mu \mathrm{m}$-thick LuAG:Ce (lutetium-aluminium-garnet) crystal. The resulting detected spectrum was then centred on $77 \mathrm{keV}$, with a bandwidth of $17 \mathrm{keV}$ FWHM (full width at half maximum). The detector was a FreLoN $2 \mathrm{~K}$ charge coupled device (CCD) camera mounted on a lens 
system. To obtain a sufficient propagation phase-contrast effect, a distance of $3 \mathrm{~m}$ between the sample and the detector was used. Synchrotron data were reconstructed using a filtered back-projection algorithm coupled with a single distance phase-retrieval process (Paganin et al., 2002; Sanchez et al., 2012). All the sub-scans were reconstructed separately, converted into 16-bit TIFF stacks and then concatenated to generate a single complete volume. The ring artefacts were corrected on the reconstructed slices using a specific tool developed at the ESRF (Lyckegaard et al., 2011). The final volume

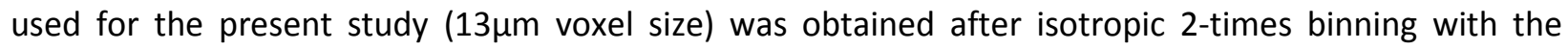
software ImageJ.

Stage 2 - Pup 1 (with yolk sac) (CCC 29.5)

The specimen was scanned on the ID19 beamline on the ESRF in a empty plastic tube, at a voxel size of $23.34 \mu \mathrm{m}$, using a propagation distance of $13 \mathrm{~m}$ to maximize the phase-contrast effect. The beam produced by the W150 wiggler at a gap of $59 \mathrm{~mm}$ was filtered by $2.8 \mathrm{~mm}$ of aluminium and $1.4 \mathrm{~mm}$ of copper, resulting in an average detected energy of $77,4 \mathrm{keV}$. The scintillator was a $2000-\mu \mathrm{m}$-thick LuAG:Ce (lutetium-aluminium-garnet doped with cerium) crystal. The detector was a PCO edge 4.2 sCMOS. Tomographic slices were reconstructed using the same protocol than the one described above. The final volume $(46.68 \mu \mathrm{m}$ voxel size) was obtained after isotropic 2 -times binning with the softward ImageJ.

Stage 3 - Pup 2 (with yolk sac resorbed) (CCC 162.21)

The specimen was scanned in a similar manner to stage 2 , at a voxel size of $23.34 \mu \mathrm{m}$. The scintillator, detector and distance between the sample and the detector were the same as for the stage 2 embryo. The final volume $(46.68 \mu \mathrm{m}$ voxel size) was obtained after isotropic 2 -times binning in ImageJ.

Stage 4 - Juvenile (CCC 94)

The specimen was scanned twice, once at the ESRF on the beamline ID19, and once using magnetic resonance imaging (MRI). At the ESRF, the specimen was scanned in a plastic tube filled with water, at a voxel size of $28.43 \mu \mathrm{m}$, using a propagation distance of $13 \mathrm{~m}$ to maximize the phase-contrast effect. The beam produced by the W150 wiggler at a gap of $30 \mathrm{~mm}$ was filtered by $2 \mathrm{~mm}$ of aluminium and $15 \mathrm{~mm}$ of copper, resulting in an average detected energy of $170 \mathrm{keV}$ with a bandwidth of $85 \mathrm{keV}$ FWHM. The 
detector camera was a FreLoN 2K charge coupled device mounted on a lens system coupled to a 750-mmthick LuAG:Ce scintillator. Tomographic slices were reconstructed using the same protocol than the ones described above. The final volume ( $56.86 \mu \mathrm{m}$ voxel size) was obtained after isotropic 2-times binning with the software ImageJ.

As the contrast was not sufficient due to the partial demineralisation of the bones linked to the long preservation in formalin solution, the specimen was re-scanned using MRI at lower resolution. The MRI was performed at 3T with a Siemens Tim TRIO (Siemens, Germany) system. Images were acquired with a 3D Flash sequence using an isotropic resolution of $300 \mu \mathrm{m}$. Parameters were: Matrix size $=640 * 300 * 256$; $\mathrm{TR} / \mathrm{TE}(\mathrm{ms})=18 / 4.73$; Flip Angle $=10^{\circ}$; Spectral Width = $100 \mathrm{kHz}$; Number of averages = 20; Total acquisition time was 7 hours and 41 minutes.

Stage 5 - Adult (CCC 27)

The specimen CCC 27 was scanned at the AST-RX facility of the MNHN (Paris, France) using stacking of multiple scans with the following scanning parameters: voltage $110 \mathrm{kV}$, current $950 \mu \mathrm{A}$, filter $0.2 \mathrm{~mm} \mathrm{Cu}$, voxel size $105 \mu \mathrm{m}$ and 3,258 views.

Segmentation and 3D-reconstruction method

For all the specimens, segmentation and three-dimensional rendering were done using the softwares MIMICS Innovation Suite 20.0 (Materialise) (Stage 1-4) and MIMICS Innovation Suite 21.0 (Materialise) (Stage 5). The different objects were exported in STL format and transformed into a 3D PDF with the software 3-matic 11.0 (Materialise) (Stages 1-4) and 3-matic 13.0 (Materialise) (Stage 5).

\section{Results:}

The pelvic appendages are located on the ventral side of the animal, in the middle of the body on both sides of the cloaca (Millot et al., 1978).

The pelvic girdle

This article is protected by copyright. All rights reserved. 
In the adult stage, the pelvic girdle is a massive element and supports several processes: the anterior process (ant.p) ("segment antérieur" according to Millot and Anthony), the lateral process (lat.pro.) ("apophyse latérale externe" according to Millot and Anthony), the medial process (med.pro) ("apophyse latérale interne" according to Millot and Anthony) and the postero-superior process (ps.pro) ("apophyse postéro-supérieure" according to Millot and Anthony) (Figs. 2E-3). The anterior process is a long cartilaginous and rod-like structure that gently flares anteriorly to form a flattened blade. The lateral process is large and flat, concave on its dorsal side, with an anterior peak, whereas the medial process is a short and triangular expansion. The postero-superior process is robust and short, with a flattened apex. The posterior part of the girdle presents a convex articular head, called the acetabulum, which articulates with the first axial element of the fin. The two girdles are not fused in Latimeria (Fig. 4C), but joined by ligaments between the two medial processes and between the distal edge of the two anterior processes. The microtomographic data allow, for the first time, the visualization of a partially denser region at the surface of the pelvic girdle that could correspond to an endochondral ossification of the girdle (Figs. 2E-34). In the adult, this region covers the anterior process, the medial process, and extends posteriorly until the base of the postero-superior process and of the lateral process with a convex expansion. This denser area is internally associated with a trabecular system (Figs. 2E-4B) that is well developed in the posterior part and the medial process of the girdle. The anterior process and the base of the lateral process present a trabecular system appears to be less developed. This ossification is also visible on the isolated pelvic girdle of the specimen CCC 7.

In the fetus, the pelvic girdle is relatively smaller and shows a very different shape from what is observed in the next stages (Fig. 5A). The different processes have morphologies different from those observed in the adult stage. The anterior process of the girdle is only represented by a small pointed extension. The medial process is large with a square shape and the lateral process forms only a short crest. The posterosuperior process is a reduced convex process. From pup 1 onwards, the girdle becomes more complete and all its processes are fully formed (Fig. 5B-E). In pup 1, the anterior process of the right girdle does not form a blade, but a bifid process. The dense superficial surface only partially covers the anterior process of the girdle (Fig. 5B). From pup 2 onwards, the anterior process of the girdle forms a blade. The dense 
superficial surface covers almost the entire anterior process of the girdle, and the most anterior part of the girdle (Fig. 5C). In the juvenile, the ossification expands to the posterior part of the girdle and partially covers the medial process (Fig. 5D). No trabecular system can be observed, in contrast to the adult stage.

The pelvic fin (Fig. 6)

The pelvic fin is composed of several elements: mesomeres on the metapterygial axis, pre-axial elements (pre-axial radials + pre-axial accessory elements) and post-axial elements (post-axial radials + distal radial). According to Millot and Anthony (1958), the metapterygial axis of the fin consists of five axial elements (named "articles"), numbered from proximal to distal, while Forey (1998) identified 4 mesomeres and one distal radial element. There are five pre-axial radial elements (Millot and Anthony, 1958; Forey, 1998), a variable number of pre-axial accessory elements and post-axial radials (Millot and Anthony, 1958). The fin rays insert on the pre-axial and post-axial elements of the fin (see descriptions below). As described by Millot and Anthony (1958), the so-called "fifth article" of the metapterygial axis has a different shape compared to the previous elements of the metapterygial axis, and the fin rays insert on it. Following Forey (1998), we therefore consider this element as a distal radial belonging to the post-axial elements (Fig. 6). In the adult stage, the organization of the endoskeleton of the pelvic fin is similar to that observed for the pectoral fin (Millot and Anthony, 1958; Mansuit et al., 2019) (Fig. 7). However, unlike in the pelvic girdle, there is no trabecular system in any element of the pelvic fin (as for the pectoral fin) (Fig. 2).

\section{1) The metapterygial axis}

As for the pectoral fin of L. chalumnae (Mansuit et al., 2019), we use the term mesomere for subcylindrical radial segments of the principal axis in sarcopterygian fins (Jarvik, 1980).

As described by Millot and Anthony (1958) for the adult stage, the four mesomeres have a similar length, and the three first mesomeres have a similar shape (Fig. 6A). There is a progressive dorso-ventral flattening of the mesomeres from proximal to distal (Fig. 6B). From proximal to distal, the ridges on the dorsal side of the mesomeres are also progressively less developed and have an increasingly medial position from the first to the third mesomere.

- $\quad$ The first mesomere (mes.1) 
As described by Millot and Anthony (1958) in the adult stage the first mesomere is wider than long and slightly arc-shaped. It articulates with the acetabulum of the pelvic girdle by its concave proximal edge and with the next mesomere by its convex distal edge (Fig. 6). The angle between the distal edge and the medial edge forms a large process. The dorsal side presents a strong but irregular oblique crest, directed from proximo-lateral to disto-medial. The ventral facet of the mesomere is flatter with only a small swelling on the medial part of its surface.

In the fetus, the shape of the first mesomere is similar to that seen in the adult specimen: concave on the proximal edge and convex on the distal edge, with a ridge on its dorsal face (Fig. 7A). There is a bilateral asymmetry to the morphology of the mesomere, since the ridge is oblique on the right fin whereas it is longitudinal on the left fin (Fig. 10A). This first mesomere is squarer in the fetus than in the adult stage. There is no process on the medial side of the mesomere. The ventral side of the mesomere does not have a swelling on the medial part of the surface, but a longitudinal ridge close to the medial edge. From pup 1 onwards, the first mesomere has already its adult shape, arc-shaped and slightly wider than long (Fig. 7B-E). The dorsal ridge is well developed, with an irregular surface. In pup 1, the ventral face of the first mesomere has an important swelling on the medial part of its surface. From pup 2 onwards, the swelling is less important and the ventral side of the mesomere is flatter. The oblique crest on the ventral face of this mesomere described by Millot and Anthony (1958) is not present from pup 1 onwards, neither is it on the isolated pelvic fin.

- $\quad$ The second mesomere (mes.2)

In the adult stage, the second mesomere has a morphology similar to that of the first mesomere, but more flattened and slightly shorter (Fig. 6). The medial process is smaller and the dorsal ridge less developed. The latter is less oblique and more latero-medially oriented than on the mesomere 1.

In the fetus, the second mesomere is trapezoid in shape. There is no process on its medial edge, and the ridge is poorly developed (Fig. 7A). Moreover, this ridge is longitudinal on the left fin whereas it is more oblique on the right fin (Fig. 10A). From pup 1 onwards, the second mesomere has its adult shape (Fig. 
7B-E). As for the first mesomere, the swelling surface on the ventral face of the second mesomere is well marked in pup 1, yet becomes flatter from pup 2 onwards.

- $\quad$ The third mesomere (mes.3)

In the adult stage, the length of this element is smaller than those of previous mesomeres, but the width is more or less the same (Fig. 6). The general morphology is boomerang-liked. Like for the previous mesomeres the dorsal ridge is well developed, but less pronounced. However, the medial process is barely visible.

In the fetus, the third mesomere is square in shape, with a proximo-lateral extension (Fig. 7A). This extension could correspond to the second pre-axial radial in a fragmentation process of this early mesomere. The dorsal ridge is longitudinal and in medial position. From pup 1 onwards, the third mesomere has its boomerang shape and its well-developed ridge, as in the adult (Fig. 7B-E). As for the previous mesomeres, the ventral side of the third mesomere has an important swelling that becomes flatter from pup 2 onwards.

- The fourth mesomere (mes.4)

In the adult stage, this mesomere is trapezoid in shape, less wide than the previous mesomeres and without the presence of a medial process (Fig. 6). The proximal edge of the mesomere is slightly concave and the distal edge slightly convex, whereas the lateral and medial edges are straight. This mesomere is the only one in contact with the post-axial elements. The medial edge of this mesomere is thinner than the lateral edge. As for the previous mesomeres, there is a small ridge on the dorsal side of this mesomere. This ridge has a proximo-distal orientation and decreases in height from proximal to distal. This element is not aligned with the previous axial elements, but is medially shifted. It is surrounded by the pre-axial radial 3, the pre-axial radial 4 , the distal radial, and the post-axial radials from its pre-axial side (corresponding to its lateral edge) to its post-axial side (corresponding to the medial edge).

In the fetus, the fourth mesomere of the right fin presents an arrowhead-shape, wider than long with a strongly concave proximal edge (Fig. 7A). The shape of the left mesomere is elongated, with a slightly 
concave proximal edge (Fig. 10A). From pup 1 onwards, the mesomere has its trapezoidal shape, as in the adult (Fig. 7B-E).

\section{2) The pre-axial elements}

The pre-axial elements are situated on the lateral edge of the pelvic fin. The organization of the radial elements along the metapterygial axis is similar on the pelvic fin and on the pectoral fin, except for the presence of a pre-axial radial (called pre-axial radial 0) on the pelvic fin only (Fig. 7). As in the pectoral fin (Millot and Anthony, 1958; Mansuit et al., 2019) there is an important difference in morphology of the pre-axial radial elements between the most proximal elements (pr.rad. 0-2) and the distal elements (pr.rad. 3-4).

- $\quad$ The pre-axial radial 0 (pr.rad.0)

In the adult stage, this element has a square shape and lies in the prolongation of the lateral edge of the first mesomere. It is in contact with the ventral side of the latero-distal part of the pelvic girdle (Fig. 6). The medial articular surface of the pre-axial radial 0 , in contact with the pelvic girdle, is slightly concave. In the fetus, this element is rectangular in dorsal view with a triangular section (Fig. 7A). From pup 1 onwards, this element is square in shape (Fig. 7B-E).

- $\quad$ The pre-axial radial 1 (pr.rad.1)

In the adult stage, this element forms the prolongation of the lateral edge of the second mesomere and is in contact with the lateral part of the distal edge of the first mesomere (Fig. 6). The pre-axial radial 1 is formed by two parts, a large and rectangular proximal element and a small distal element with a triangular shape.

In the fetus, this element is single and elongated (Fig. 7A). In pup 1, this element is also single and rectangular in shape (Fig. 7B). In pup 2, the pre-axial radial 1 is fully formed and composed of two elements (Fig. 7C-E). In the juvenile, only one element can be reconstructed from the MRI scans but this may be due to the lack of precision in the MRI data (Fig. 7D). 
- $\quad$ The pre-axial radial 2 (pr.rad.2)

In the adult stage, the pre-axial radial 2 forms the prolongation of the lateral side of the third mesomere and lies in contact with the lateral part of the distal edge of the second mesomere (Fig. 6). The pre-axial radial 2 is formed by two elements, a basal square element, adjacent to the mesomere 3 , and a rectangular element aligned with the basal element (Fig. 7B). This element carries fin rays 1-6 on its dorsal side, whereas it only carries the fin rays 1-4 inserting more distally on its ventral side (Fig. 9).

In the fetus, this element does not appear individualized from the mesomere 3. From pup 1 onwards, the pre-axial radial 2 has its adult shape, with its elongated rectangular shape and the two aligned pieces (Fig. 7B). There is some variation in the morphology of this element as in pup 2 and the juvenile specimens the pre-axial radial 2 only consists of a single elongated element (Fig. 7C-D), instead of two aligned elements (Fig. 7B, E). However, these observations could be due to the low resolution of the MRI data of the juvenile specimen.

- $\quad$ The pre-axial radial 3 (pr.rad.3)

In the adult stage, the pre-axial radial 3 is a thin and elongated element, longer than the fourth mesomere, with three straight edges and one distal convex edge (Fig. 6). The proximal edge of this element is straight and articulates with the third mesomere. A very small globular element is present at its distal tip. This preaxial radial carries the fin rays 10-13 (Fig. 9).

In the fetus, this element is not separated from the fourth mesomere (Fig. 7A, Fig. 10A). In pup 1, the preaxial radial 3 is thin and elongated, without a separated tip (Fig. 7B). Its medial edge is straight and its latero-distal corner forms a concave angle to fit a pre-axial accessory element. This angle could correspond to some elements of pre-axial accessory elements that are segmented later in the pup 2 to form the three most distal elements (Fig. 7B-C). On the left fin, the distal part of the radial is surrounded by the pre-axial radial 4 . From pup 2 onwards, this element has its adult shape, with an elongated trapezoidal shape and a separated distal small element (Fig. 7C-E).

- $\quad$ The pre-axial radial 4 (pr.rad.4) 
The pre-axial radial 4, situated at the distal end of the fin endoskeleton, closely resembles the mirror image of the distal radial. As the pre-axial radial 3 this element is elongated with three straight edges and a convex distal edge (Fig. 6). This element carries the fin rays 14-18 (Fig. 9).

In the fetus, the data do not allow the separation of the pre-axial radial 4 from the fin rays and muscles on the right fin (Fig. 7A), so this element was not segmented. However, it is assumed that the pre-axial radial 4 is already present on the right fin. On the left fin, this radial is not separated from the distal radial (Fig. 10A). In pup 1, there is a bilateral asymmetry, since the medial edge of the pre-axial radial 4 is straight on the right fin (Fig. 7B), but concave on the left fin, forming a space between this element and the distal radial (Fig. 10B). The lateral edge of the pre-axial radial 4 forms an angle that surrounds the distal part of the pre-axial radial 3. From pup 2 onwards, the pre-axial radial 4 has the same trapezoidal shape as described for the adult (Fig. 7C-E).

- The pre-axial accessory elements (pr.acc.)

In adult stage, these small elements (called "éléments accessoires de la troisième pièce radiale préaxiale" by Millot and Anthony, 1958) are positioned in a patch between the distal edges of the third mesomere, the pre-axial radial 2, and the lateral edge of the pre-axial radial 3 (Fig. 6). According to Millot and Anthony (1958), the pelvic fin presents four of these elements at the adult stage. However, both our segmentation of the scan of the pelvic fin and the observation of the isolated fin show a variation in the number of preaxial accessory elements. Indeed, there are 13 elements in adult stage CCC 27 (Fig. 6, Fig. 7E), whereas there are at least five accessory elements in the isolated fin of CCC 7. The difference in numbers of elements observed in the different fins can be explained by the size of the smallest elements, not visible to the naked eyes and hidden by dermal fin rays covering them. The pre-axial accessory elements carry the fin rays 7-9 on the dorsal side of the fin and the fin rays 5-9 on the ventral side of the fin (Fig. 9).

These elements are not present in the fetus, and appear at the pup 1 stage (Fig. 7). In the pup 1 stage there are only two elements, as large as the pre-axial radials 2 (Fig. 7B). These two elements become fragmented during development since there are at least ten small elements in pup 2 (Fig. 7C), and 13 
elements in the adult. In the juvenile, we assume that the pre-axial accessory elements are present, but the MRI data did not allow the visualization of the pre-axial accessory elements.

\section{3) The post-axial elements}

- The distal radial (dis.rad.)

In adult stage, the distal radial is similar in shape to the pre-axial radial 4 as a mirror image, although almost twice as wide (Fig. 6). It has three more or less straight edges and a convex distal edge. It carries the fin rays $19-27$ (Fig. 9).

In the fetus, only the left distal radial could be segmented (Fig. 10A). We assumed that the right distal radial is also present at this stage, but as for the pre-axial radial 4 , the data did not allow the separation of this element from the muscles and the fin web. This element is small and square except for its proximal edge that is slightly concave. In pup 1, the left fin presents an ovoid space between the distal radial and the pre-axial radial 4 (Fig. 10B). Such a space is not present on the right fin (Fig. 7B). Its medial edge forms an angle that surrounds the post-axial radials in the left fin. From pup 2 onwards, the distal radial is fully formed with the trapezoidal shape observed in adult stage (Fig. 7C-E). According to Millot and Anthony (1958) there is a longitudinal ridge on the dorsal side of this element, but such a ridge does not appear on the 3D modellings nor on the observed isolated pelvic fin.

- $\quad$ The post-axial radials (po.rad.)

The post-axial radials are located at the medial edge of the pelvic fin in articulation with the fourth mesomere and the distal radial. In adult stage, Millot and Anthony (1958) described three elements among the post-axial radials. The proximal element presents a large triangular shape, and is located on the medial edge of the fourth mesomere. On the left fin of CCC 27, this element is split into a large piece and a small one (Fig. 6), whereas there is only one proximal element on the right fin, as is observed for the isolated prepared fin of CCC 7 and as described by Millot and Anthony (1958). The distal element is slightly smaller, with a quadrangular shape and located on the medial part of the distal edge of the fourth mesomere and on the medial edge of the distal radial (Fig. 6). The third element is very small compared 
to the other post-axial radials, triangular-shaped, and located between the proximal and the distal one. The post-axial radials carry the fin rays 28-34 (Fig. 9).

In the fetus these elements cannot be individually identified or separated from the mesomere 4 in the right fin (Fig. 7A; Fig. 10). In the pup 1 and pup 2 the post axial radials are well developed, but with only two elements (Fig. 7B- C).

4) The fin rays (Fig. 9)

The pelvic fin in adult stage present 37 fin rays, which are numbered 1 from the pre-axial (lateral) to 37 at post-axial (medial) side of the fin. As for the pectoral fin, the proximal part of each fin ray is bifurcated, one branch inserting on the dorsal face of the fin and one branch inserts on the ventral face of the fin. The first ray is very small, and the next rays become longer along the pre-axial side of the fin, up to the axis of the fin, to progressively decrease in size along the post-axial side of the fin. As for the pectoral fin, the rays of the pre-axial side of the fin insert largely on the pre-axial elements, whereas the rays on the post-axial side of the fin insert only on the medial edges of the distal radial and the post-axial radials. The three last fin rays 35-37 are free and do not insert on fin elements. The fins rays are inserted more proximally on the dorsal than on the ventral side on the pre-axial side of the fin.

\section{Discussion:}

As discussed in our previous study (Mansuit et al., 2019), even if the gestation time for coelacanths is estimated at more to 13 months (Hureau and Ozouf, 1977), it is not possible to precisely determine the time between the different stages.

\section{Morphology of the pelvic girdle}

Unlike the pectoral girdle, the pelvic girdle is only formed by a unique endoskeletal bone as described by Millot and Anthony (1958). Unlike in lungfishes as Neoceratodus (Boisvert et al., 2013) the two hemigirdles are not fused (Fig. 4C) but only linked by ligaments (Millot and Anthony, 1958). The general shape of the pelvic girdle of Latimeria chalumnae is similar to what is observed in fossil coelacanths with an anterior rod-like process, a lateral and a medial processes (Forey, 1998). According to Forey (1998), the 
lateral process corresponds to the ilium (iliac process of Coates and Ruta, 2007), the medial process to the ischium (ischial process of Coates and Ruta, 2007) and the anterior process to the pubis of the pelvic girdle of tetrapods. However, the homology between the lateral and medial processes with the illium and ischium remains uncertain (Ahlberg, 1989). Therefore we preferred to use the neutral terminology proposed by Millot and Anthony (1958) (i.e., medial and lateral processes, and anterior process) to avoid any ambiguities regarding the homology of these structures. In extant tetrapods, the ilium, ischium and pubis are formed through different ossification centers (Malashichev, 2001; Rocková and Rocek, 2005; Maxwell and Larsson, 2009). In the extant coelacanth Latimeria, as in lungfish (Schultze, 1986) the girdle is cartilaginous (Millot and Anthony, 1958) and there is only an ossification of the anterior part of the girdle and medial process, but not for the lateral process (Fig. 2E-3-4). Moreover, the ossification of the pelvic girdle begins at the anterior process of the girdle, subsequently extending to the medial process of the girdle (Fig. 5). Consequently, only a single ossification center appears to be present in the pelvic girdle of Latimeria. Only based on anatomical observations, it is thus not possible to assign a homology to the different parts of the girdle in Latimeria relative to the different bones of the girdle of tetrapods.

The anterior process/blade of the pelvic girdle seems to be common in actinopterygian fishes (e.g., Andrews and Westoll, 1970; Grandel and Schulte-Merker, 1998; Faustino and Power, 1999; Yamanoue et al., 2010) and sarcopterygian fishes (Andrews and Westoll, 1970; Forey, 1998; Boisvert et al., 2013). According to Andrews \& Westoll (1970), this anterior process forms an insertion area for abdominal muscles and ligaments. In Latimeria, however, only the extremity of this process supports the abdominal muscles. The main part of the blade forms the attachment site for the pelvic fin muscles (Millot and Anthony, 1958) (personal observations).

As for the articular head of the pectoral girdle (Millot and Anthony, 1958), the acetabulum of the pelvic girdle of Latimeria is convex. This convex articular surface is a feature shared by coelacanths and dipnomorphs (Shubin, 1995; Boisvert et al., 2013). In tetrapodomorphs, the pelvic girdle shows a concave acetabulum, where the first mesomere fits (Ahlberg, 1989; Shubin, 1995; Boisvert et al., 2013). A concave acetabulum was considered as the primitive condition for sarcopterygians (Ahlberg, 1989), and the convex acetabulum of coelacanths and dipnomorphs as a derived character. Even if the precise interrelationships 
of sarcopterygians remain debated, the current consensus presents coelacanths as sister-taxa of tetrapods and lungfishes (e.g., Ahlberg, 1991; Cloutier and Ahlberg, 1996; Friedman et al., 2007; Amemiya et al., 2013). It thus appears that a convex acetabulum is the primitive condition for sarcopterygians.

The micro-tomographic imaging highlights, for the first time, the presence of a dense surface around part of the pelvic girdle, and the presence of a dense trabecular system within the girdle (Fig. 4B). The pelvic girdle of Latimeria is cartilaginous (Millot and Anthony, 1958; Forey, 1998), and this dense surface and trabecular system might be an endochondral ossification of the girdle. The presence of a trabecular system in the pelvic girdle of Latimeria might reinforce its structural resistance when loaded by pelvic muscle forces. Indeed, many levator and depressor muscles of the pelvic fin insert on the anterior part of the girdle and on the medial process (Millot and Anthony, 1958) (personal observations). In tetrapods, it has been shown that the ossification of the bones is influenced by muscular activity during the embryonic development (Hall, 1986; Newman and Müller, 2005; Boisvert et al., 2013). It is therefore likely that the same process occurs in Latimeria where the young develop in the mother and likely show muscular contractions before birth. The ossification of the bone occurs only from the pup 1 stage. Forey (1998) noted that the pelvic girdle of extinct coelacanths often presents an open concave posterior end, and that the acetabulum is missing. It could be assumed that only the ossified part of the pelvic girdle is preserved in the fossil record, and that the cartilaginous posterior part of the girdle does not fossilize. The trabecular system highlighted in Latimeria has never been described in the fossil records for coelacanths and other osteichthyan fishes, and remains to be determined whether this feature is specific to Latimeria or if other bony fishes possess a trabecular system in the pelvic girdle.

\section{Morphology of the pelvic fin}

In Latimeria, the general organization of the pelvic fin endoskeleton is similar to that of the pectoral fin (Millot and Anthony, 1958; Panchen and Smithson, 1990), particularly the distal part of the fin (pr.rad. 34, pr.acc., dis.rad., po.rad.) (Fig. 7). This endoskeletal morphology of the pectoral and pelvic fins/limbs is shared by all sarcopterygians (Rosen et al., 1981). In all crown-sarcopterygians these paired appendages are connected to their respective girdle via a mono-basal articulation (Rosen et al., 1981; Janvier, 1996; Clack, 2012), whereas stem-sarcopterygians are assumed to have a poly-basal fin articulation (Zhu and Yu, 
2009). In Latimeria and in other sarcopterygian fishes, the pelvic fin is smaller than the pectoral one (e.g., Andrews and Westoll, 1970; Ahlberg, 1989; Forey, 1998; Boisvert, 2005; Jeffery et al., 2018). The major difference between the pelvic and pectoral fins, in Latimeria, lies in the presence of a pre-axial radial 0 , which articulates with the pelvic girdle and the first mesomere (Fig. 7B). This element is absent in the pectoral fin (Fig. 7A). The pre-axial radial 0 was previously described (Millot and Anthony, 1958) and is also present in the pelvic fin of the Triassic coelacanth Laugia groenlandica (Stensiö, 1932) (specimen NHMD 152716, personal observation), but never received developmental or phylogenetic consideration. Indeed, the presence of this small element questions the mono-basal condition of the pelvic fin of Latimeria and coelacanths in general, and may question the synapomorphy of crown-sarcopterygians (a mono-basal articulation of paired fins (Rosen et al., 1981; Janvier, 1996; Zhu and Yu, 2009)). The development of the pelvic fin suggests that the presence of this element in contact with the girdle is due to the particular morphology of the mesomeres. This element may correspond to the pre-axial radial 1 of the pectoral girdle (see below). Thus, the pluri-basal condition of the pelvic fin of Latimeria would be a specificity of coelacanths.

Although the general organization of the endoskeleton of the pelvic and pectoral fins are similar, some differences can be observed (Fig. 6). The mesomeres of the pectoral fin are longer than wide, with a quadrangular shape (Millot and Anthony, 1958; Mansuit et al., 2019). By contrast, the mesomeres of the pelvic fin are shorter than wide with an arc shape, dorso-ventrally flattened, with a ridge on their dorsal side. These differences between the shape of the mesomeres of the pelvic and pectoral fin appears to be also present in the Triassic coelacanth Laugia groenlandica (Stensiö, 1932) (personal observations).

There are marked differences in the size and shape of the most proximal radial elements between the pectoral and pelvic fins. The pre-axial radials 1-2 of the pectoral fin are small compared to the mesomeres, ovoid in shape, and in contact with the distal part of the associated mesomere (Fig. 7A). By contrast, the pre-axial radials 1-2 of the pelvic fin are proportionally larger and in contact with both the associated and the following mesomeres (Fig. 6, Fig. 7B). In the fossil tetrapodomorph fishes Eusthenopteron and Panderichthys, the pre-axial radials 1-2 of the pelvic fin have a similar shape, although slightly smaller, than those of the pectoral fin (Andrews and Westoll, 1970; Boisvert, 2005). Their morphology is different 
from that of Latimeria: they are elongated elements that articulate with the distal edge of the associated mesomere, and more or less parallel to the long edge of the following mesomere.

According to Forey (1998), the pelvic fin of Latimeria presents an important degree of asymmetry to the central axis compared to the pectoral fin, i.e. the organization and arrangement of the elements is different between the pre-axial and the post-axial edge of the fin. As for the pectoral fin (Millot and Anthony, 1958; Mansuit et al., 2019), the arrangement of the pre- and post-axial elements along the metapterygial axis of the pelvic fin of Latimeria is asymmetrical. The mesomeres of the pelvic fin are all associated with pre-axial radials, whereas only the fourth mesomere is associated with post-axial elements (post-axial radials and distal radial). Moreover, the presence of the pre-axial radial 0 on the pelvic fin, not present on the pectoral fin, increases the asymmetry to the central axis of the pelvic fin. However, as for the pectoral fin, the most proximal pre-axial radials (0-2) of the pelvic fin are small and globular or rectangular shape, whereas the distal pre-axial radials (3-4) are thin and elongate (Millot and Anthony, 1958) (Fig. 6). This difference of shape is related to muscle insertions. Indeed, some muscles insert on the pre-axial radials 0-2, whereas for the pre-axial radial 3-4, the muscles inserted at the base of the fin rays that are associated with the radials (Mansuit et al., in prep.). Considering the general endoskeletal arrangement, the pelvic fin of Latimeria shows a short lobe-shaped silhouette compared to that of the more elongate lobed pectoral fin. The insertion of the fin rays on the fin is also more asymmetrical on the pelvic fin compared to the pectoral fin (Millot and Anthony, 1958; Friedman et al., 2007). Fin rays of the pelvic fin insert more proximally on the pre-axial side than on the post-axial side (Fig. 9) compared to the pectoral fin where the fin web shows a more symmetrical arrangement around the metapterygial axis. However, as for the pectoral fin, the most proximal pre-axial radials (pre-axial radial 0-1) are not associated with the pelvic fin rays. An asymmetrical arrangement of the pelvic fin rays along the metapterygial axis has also been suggested in the Triassic coelacanth Laugia groenlandica (Stensiö, 1932; Forey, 1998). An asymmetry is also present on the fin ray arrangements between the dorsal and ventral sides of the pelvic fin. Indeed, the fin rays insert more proximally on the dorsal side of the fin than on the ventral side (Fig. 9). This asymmetrical coverage of the paired fin rays is also shared by 
the fossil coelacanths Laugia groenlandica (Stensiö, 1932; Forey, 1998), the extant lungfish Neoceratodus and fossil tetrapodomorph fishes, such as Eusthenopteron and Tiktaalik (Stewart et al., 2019).

Development of the pelvic appendage

The most pronounced changes in the pelvic girdle morphology occurs between the fetus and pup 1, and notably entail the elongation of the anterior part of the girdle (Fig. 5A, B). The elongation of the girdle during the development seems to be common in osteichthyan fishes, since it is observed both in actinopterygians, for example in Pagrus major (Matsuoka, 1985), Chanos chanos (Taki et al., 1986), Danio rerio (Grandel and Schulte-Merker, 1998) and Sparus aurata (Faustino and Power, 1999), and in the lungfish Neoceratodus forsteri (Boisvert et al., 2013). However, the pelvic girdle mainly grows in a posterior direction in the axolotl Ambystoma mexicanum (Boisvert et al., 2013), whereas the pubis has a small anterior growth.

Although very similar, the development of the pelvic fin appears to lag behind that of the pectoral fin in Latimeria. The assumption of a delay in the development of the pelvic appendage is based on the morphology of the endoskeletal elements observed in the fetus. At this stage, all mesomeres of the pectoral fin are formed, and the radial elements are present, at least as cartilaginous plates. However, most of the radial elements are not differentiated from the mesomere 4 and the distal radial in the pelvic fin (Fig. 8; Fig. 10A), which suggests that its development is delayed compared to the pectoral fin. A delay in the development of the pectoral and pelvic appendages is also observed in chondrichthyans (Ballard et al., 1993; Didier et al., 1998; Ziermann et al., 2017), actinopterygians (Grandel and Schulte-Merker, 1998; Faustino and Power, 1999) and sarcopterygians (Joss and Longhurst, 2001; Boisvert et al., 2013). Therefore, Latimeria likely follows the general gnathostome pattern of paired appendages development. In Latimeria fetus, only the most proximal pre-axial radials (pr.rad. 0-1) are present in the pelvic fin (Fig. 8). However, from pup 1 stage onwards all the elements of the fin are present. Contrary to what is observed during the development of the pectoral fin (Mansuit et al., 2019), there is no cartilaginous plate around the metapterygial axis of the pelvic fin. 
Based on the comparison of the morphology of the mesomeres during the development, we suggest a developmental mechanism for the endoskeletal elements of the pelvic fin. Along the pre-axial edge of the fin, the distribution of the radials matches that of the mesomeres (e.g. mes.1 and pr.rad.0) in the pups and adult. In the fetus, only the radial 0 and 1 are present. In addition, the mesomere 3 presents a general shape that is different from that observed in later stages, with the presence of a well-developed proximolateral extension (Fig. 8; Fig. 10A). Similarly, the mesomere 4 (observed in the right pelvic fin), which is the most distal endoskeletal element in the fetus fin, has an arrow-head shape with lateral and medial extensions around the distal end of the mesomere 3. These lateral extensions of the mesomeres 3 and 4 are lost in later developmental stages (Fig. 8), while there is a progressive increase in the number of elements on the pre-axial side of the fin. An additional pre-axial radial and two pre-axial accessory elements are observed in pup 1, and the number of pre-axial accessory elements increases in pup 2 (10) and in the adult (13) (Fig. 8). This pattern suggest that the pre-axial radials are formed through the fragmentation of the radial extension of the adjacent mesomere, following a proximo-distal sequence during the development (i.e. the first mesomere splits first). In this scenario, the extension of mesomere 3 observed in the fetus gives rise to the pre-axial radial 2 in the pup. From pup 1 onwards, a series of preaxial and post-axial radials surrounds the mesomere 4 . We suggest that these elements derive respectively from the lateral and medial extensions of the mesomere 4 observed in the fetus. The distal end of the left fin is formed by a distal plate in the fetus, which might correspond to the distal radial and the pre-axial radial 4 from pup 1 onwards (Fig. 10). Yet, additional developmental stages are needed to better understand the origin of the distal elements of the pelvic fin, such as the pre-axial radial 3 , and the potential contribution of the mesomere 4 and distal plate in the formation of these elements.

The formation of the pre-axial radials is not clearly understood in the extant lungfish Neoceratodus. Previous studies suggest two different patterns of development to explain their formation. In the first scenario, the radials arise de novo process (Joss and Longhurst, 2001): they are formed by a distinct mesenchymal condensation and are unconnected to other elements (Shubin and Alberch, 1986; Johanson et al., 2007). In the second scenario, the radials arise from the fragmentation of the associated mesomere (Joss and Longhurst, 2001), i.e. the element is formed by a continuous plate of precartilage that 
subsequently breaks up into two separate elements (Shubin and Alberch, 1986). This second scenario could corroborate our hypothesis of the splitting of the mesomere. However, we suggested previously that the pre-axial radials are formed by the fragmentation of the following mesomeres, and not the associated mesomeres as in Neoceratodus. Since the mesomeres of the pelvic fin of Latimeria have an arc-shape it is possible that the position of the pre-axial radials is different compared to that observed for the pectoral fin. If so, this would suggest that the pre-axial radial 0 of the pelvic fin corresponds to the pre-axial radial 1 of the pectoral fin (and the pr.rad. 1 of pelvic fin to the pr.rad. 2 of the pectoral fin). The pre-axial radial 3 of the pelvic fin would then not correspond to any pre-axial radial in the pectoral fin, and this element could have been lost in the pectoral fin. If there is a correspondence between pectoral and pelvic pre-axial radials, the poly-basal condition of the pelvic fin in Latimeria may be a derived character in sarcopterygians due to the shape of the mesomeres. Concerning the formation of the post-axial elements, these elements are supposed to arise de novo in Neoceratodus (Joss and Longhurst, 2001; Johanson et al., 2007), but a fragmentation process cannot be excluded in Latimeria, as explained above.

\section{Conclusion:}

As in other vertebrates, the development of the pelvic fin occurs later than that of the pectoral fin Latimeria: many elements of the endoskeleton are not formed yet in the earliest stage sampled here. In the fetus, only the four mesomeres and the most proximal radial elements (pre-axial radial 0-1) are formed. The mesomeres 3 and 4 show prominent extensions in the fetus, but not in later stages. We suggest that the radial elements (pre-axial radials 0-4, pre-axial accessory elements and post-axial radials) originate from the fragmentation of the mesomeres (e.g. pr.rad. 0 fragments from mes. 1). Since the pectoral and pelvic fins show a similar organization of their endoskeleton and development, it is most probable that the same mechanism underpins the formation of both paired fins. The progressive ossification of the pelvic girdle and the formation of a trabecular system in the adult stage is documented here. This trabecular system might reinforce the cartilaginous girdle to withstand the muscle forces exerted during locomotion. However, it remains unknown whether this trabecular system is unique to Latimeria chalumnae or shared by other extinct coelacanths or early sarcopterygians. Finally, the presence of a pre-axial element in contact with the pelvic girdle from the earliest stage of development onwards 
questions the mono-basal condition of the pelvic fin in Latimeria. The presence of this element raises questions a synapomorphy of crown-sarcopterygians: the mono-basal articulation of paired fins. But the particular shape of the mesomeres of the pelvic fin and the process of development of pre-axial radials may explain the presence of this element in contact with the girdle. This element could be homologous to the pre-axial radial 1 on the pectoral fin.

\section{Abbreviations}

act. $=$ acetabulum; ant.p. $=$ anterior process; lat.p. = lateral process; med. pro. $=$ medial process; mes. $=$ mesomere; po.rad. = post-axial radial; pos.p. = posterior part; pr.acc. = pre-axial accessory elements; pr.rad. $=$ pre-axial radial ps. pro. $=$ postero-superior process

\section{Data Availability Statement}

The synchrotron data will be available on the ESRF database, at the following address: http://paleo.esrf.fr/ (fetus, pup1, pup2, juvenile). The CT-scan data are available at the following address: http://coldb.mnhn.fr/catalognumber/mnhn/za/ac-2012-21 (adult). The MRI data will be available at the following address: https://www.morphosource.org/ (juvenile). All the data are also available by request from the authors. 


\section{Acknowledgments}

We thank R. Bills and A. Paterson (South African Institute for Aquatic Biodiversity, SAIAB) and D. Neumann (Zoologische Staatssammlung München, ZSM) for the loan of the fetus and pup 2 specimens, respectively. We are grateful to the European Synchrotron Radiation Facility (ESRF, Grenoble, France) for granting beam time and providing assistance in using beamline ID19 (Proposal EC-1023), and M. Garcia and M. Bellato at AST-RX, plate-forme d'accès scientifique à la tomographie à rayons X (UMS 2700, MNHN, Paris, France) for the X-ray tomography scans. We thank F. Goussard (UMR 7207 CR2P MNHN-CNRS-Sorbonne Université, Paris, France) for his assistance in the 3D imaging work. We thank C. Bens and A. Verguin of the Collections de Pièces anatomiques en Fluides of the MNHN de Paris. We thank B. Lindow (Natural History Museum of Denmark) for the loan of fossils of Laugia groenlandica. This work was supported by a grant from Agence Nationale de la Recherche in the LabEx ANR-10-LABX-0003-BCDiv, program 'Investissements d'avenir' no ANR-11-IDEX-0004-02. 


\section{Literature cited:}

Ahlberg, P. E. 1989. Paired fin skeletons and relationships of the fossil group Porolepiformes (Osteichthyes: Sarcopterygii). Zoological Journal of the Linnean Society 96:119-166.

Ahlberg, P. E. 1991. A re-examination of sarcopterygian interrelationships, with special reference to the Porolepiformes. Zoological Journal of the Linnean Society 103:241-287.

Amemiya, C. T., J. Alfoldi, A. P. Lee, S. Fan, H. Philippe, I. MacCallum, I. Braasch, T. Manousaki, I. Schneider, N. Rohner, C. Organ, D. Chalopin, J. J. Smith, M. Robinson, R. A. Dorrington, M. Gerdol, B. Aken, M. A. Biscotti, M. Barucca, D. Baurain, A. M. Berlin, G. L. Blatch, F. Buonocore, T. Burmester, M. S. Campbell, A. Canapa, J. P. Cannon, A. Christoffels, G. De Moro, A. L. Edkins, L. Fan, A. M. Fausto, N. Feiner, M. Forconi, J. Gamieldien, S. Gnerre, A. Gnirke, J. V. Goldstone, W. Haerty, M. E. Hahn, U. Hesse, S. Hoffmann, J. Johnson, S. I. Karchner, S. Kuraku, M. Lara, J. Z. Levin, G. W. Litman, E. Mauceli, T. Miyake, M. G. Mueller, D. R. Nelson, A. Nitsche, E. Olmo, T. Ota, A. Pallavicini, S. Panji, B. Picone, C. P. Ponting, S. J. Prohaska, D. Przybylski, N. R. Saha, V. Ravi, F. J. Ribeiro, T. Sauka-Spengler, G. Scapigliati, S. M. J. Searle, T. Sharpe, O. Simakov, P. F. Stadler, J. J. Stegeman, K. Sumiyama, D. Tabbaa, H. Tafer, J. Turner-Maier, P. Van Heusden, S. White, L. Williams, M. Yandell, H. Brinkmann, J. N. Volff, C. J. Tabin, N. H. Shubin, M. Schartl, D. B. Jaffe, J. H. Postlethwait, B. Venkatesh, F. Di Palma, E. S. Lander, A. Meyer, and K. Lindblad-Toh. 2013. The African coelacanth genome provides insights into tetrapod evolution. Nature 496:311-316.

Andrews, S. M., and T. S. Westoll. 1970. The Postcranial Skeleton of Eusthenopteron foordi Whiteaves. Earth and Environmental Science Transactions of the Royal Society of Edinburgh 68:207-329.

Ballard, W. W., J. Mellinger, and H. Lechenault. 1993. A series of stages for development of Scyliorhinus canicula the lesser spotted dogfish (Chondrichthyes: Scyliorhinidae). Journal of Experimental Zoology 267:1-43.

Boisvert, C. A. 2005. The pelvic fin and girdle of Panderichthys and the origin of tetrapod locomotion. Nature 438:1145-1147.

Boisvert, C. A., J. M. Joss, and P. E. Ahlberg. 2013. Comparative pelvic development of the axolotl (Ambystoma mexicanum) and the Australian lungfish (Neoceratodus forsteri): conservation and innovation across the fish-tetrapod transition. EvoDevo 4:1-19.

Clack, J. A. 2012. Gaining Ground: The Origin an Evolution of Tetrapods. Indiana University Press, Bloomington, 1-523 pp.

Cloutier, R., and P. E. Ahlberg. 1996. Morphology, Characters, and the Interrelationships of Basal Sarcopterygians. Interrelationships of Fishes 445-479.

Coates, M. I., and M. Ruta. 2007. Skeletal Changes in the Transition from Fins to Limbs; pp. 15-38 in Fins into Limbs - Evolution, Development, and Transformation. The University of Chicago Press, Chicago. 
Cubbage, C. C., and P. M. Mabee. 1996. Development of the cranium and paird fins in the zebrafish Danio rerio (Ostariophysi, Cyprinidae). Journal of Morphology 229:121-160.

Cupello, C., P. M. Brito, M. Herbin, F. J. Meunier, P. Janvier, H. Dutel, and G. Clément. 2015. Allometric growth in the extant coelacanth lung during ontogenetic development. Nature Communications $6: 1-5$.

Didier, D. A., E. E. Leclair, and D. R. Vanbuskirk. 1998. Embryonic staging and external features of development of the chimaeroid fish, Callorhinchus milii (Holocephali, Callorhinchidae). Journal of Morphology 236:25-47.

Dutel, H., M. Galland, P. Tafforeau, J. A. Long, M. J. Fagan, P. Janvier, A. Herrel, M. D. Santin, G. Clément, and M. Herbin. 2019. Neurocranial development of the coelacanth and the evolution of the sarcopterygian head. Nature 569:556-559.

Faustino, M., and D. M. Power. 1999. Development of the pectoral, pelvic, dorsal and anal fins in cultured sea bream. Journal of Fish Biology 54:1094-1110.

Forey, P. L. 1998. History of the Coelacanth Fishes. Chapman \& Hall, London, 1-419 pp.

Friedman, M., M. I. Coates, and P. Anderson. 2007. First discovery of a primitive coelacanth fin fills a major gap in the evolution of lobed fins and limbs. Evolution and Development 9:329-337.

Grandel, H., and S. Schulte-Merker. 1998. The development of the paired fins in the zebrafish (Danio rerio). Mechanisms of Development 79:99-120.

Hall, B. K. 1986. The role of movement and tissue interactions in the development and growth of bone and secondary cartilage in the clavicle of the embryonic chick. Journal of Embryology and Experimental Morphology 93:133-152.

Hureau, J.-C., and C. Ozouf. 1977. Détermination de l'âge et croissance du coelacanthe Latimeria chalumnae Smith, 1939 (Poisson, crossopterygien, Coelacanthidae). Cybium 2:129-137.

Janvier, P. 1996. Early Vertebrates. Clarendon Press, Oxford, 1-393 pp.

Jarvik, E. 1980. Basic Structure and Evolution of Vertebrates. Academic Press, New York, 1-575 pp.

Jeffery, J. E., G. W. Storrs, T. Holland, C. J. Tabin, and P. E. Ahlberg. 2018. Unique pelvic fin in a tetrapodlike fossil fish, and the evolution of limb patterning. Proceedings of the National Academy of Sciences 115:201810845.

Johanson, Z., J. Joss, C. A. Boisvert, R. Ericsson, M. Sujita, and P. E. Ahlberg. 2007. Fish fingers: Digit Homologues in Sarcopterygian Fish Fins. Journal of Experimental Zoology. Part B, Molecular and Developmental Evolution 308:757-768.

Joss, J. M., and T. Longhurst. 2001. Lungfish paired fins; pp. 289-306 in P. E. Ahlberg (ed.), Major events in early vertebrate evolution, Taylor \& F. London. 
Jude, E., Z. Johanson, A. Kearsley, and M. Friedman. 2014. Early evolution of the lungfish pectoral-fin endoskeleton: evidence from the Middle Devonian (Givetian) Pentlandia macroptera. Frontiers in Earth Science 2:1-15.

Lyckegaard, A., G. Johnson, and P. Tafforeau. 2011. Correction of Ring Artifacts in X-ray Tomographic Images. International Journal of Tomography \& Simulation 18:1-9.

Mabee, P. M., and T. A. Trendler. 1996. Development of the cranium and paired fins in Betta splendens (Teleostei: Percomorpha): Intraspecific variation and interspecific comparisons. Journal of Morphology 227:249-287.

Mabee, P. M., and M. Noordsy. 2004. Development of the paired fins in the paddlefish, Polyodon spathula. Journal of Morphology 261:334-344.

Malashichev, Y. B. 2001. Sacrum and Pelvic Girdle Development in Lacertidae. Russian Journal of Herpetology 8:1-16.

Mansuit, R., G. Clément, A. Herrel, H. Dutel, P. Tafforeau, M. D. Santin, and M. Herbin. 2019. Development and growth of the pectoral girdle and fin skeleton in the extant coelacanth Latimeria chalumnae. Journal of Anatomy 1-17.

Matsuoka, M. 1985. Osteological development in the red sea bream, Pagrus major. Japanese Journal of Ichthyology 32:35-51.

Maxwell, E. E., and H. C. E. Larsson. 2009. Comparative ossification sequence and skeletal development of the postcranium of palaeognathous birds (Aves: Palaeognathae). Zoological Journal of the Linnean Society 157:169-196.

Millot, J., and J. Anthony. 1958. Anatomie de Latimeria Chalumnae, Tome I : Squelette, Muscles et Formations de Soutien, CNRS. Paris, 1-122 pp.

Millot, J., and J. Anthony. 1965. Anatomie de Latimeria Chalumnae, Tome II : Système Nerveux et Organes Des Sens. 1-130 pp.

Millot, J., J. Anthony, and D. Robineau. 1978. Anatomie de Latimeria Chalumnae, Tome III : Appareil Digestif - Appareil Respiratoire - Appareil Urogenital Glandes Endocrines - Appareil Circulatoire Téguments - Ecailles - Conclusions Générale, CNRS. Paris, 1-198 pp.

Newman, S. A., and G. B. Müller. 2005. Origination and innovation in the vertebrate limb skeleton: An epigenetic perspective. Journal of Experimental Zoology Part B: Molecular and Developmental Evolution 304:593-609.

Nulens, R., L. Scott, and M. Herbin. 2011. An updated inventory of all known specimens of the coelacanth, Latimeria spp. Smithiana Publications in Aquatic Biodiversity 3:1-52.

Paganin, D., S. C. Mayo, T. E. Gureyev, P. R. Miller, and S. W. Wilkins. 2002. Simultaneous phase and amplitude extraction from a single defocused image of a homogeneous object. Journal of 
Microscopy 206:33-40.

Panchen, A. L., and T. R. Smithson. 1990. The pelvic girdle and hind limb of Crassigyrinus scoticus (Lydekker) from the Scottish Carboniferous and the origin of the tetrapod pelvic skeleton. Transactions of the Royal Society of Edinburgh: Earth Sciences 81:31-44.

Pouyaud, L., S. Wirjoatmodjo, I. Rachmatika, A. Tjakrawidjaja, R. Hadiaty, and W. Hadie. 1999. A new species of coelacanth. Life Sciences 322:261-267.

Rocková, H., and Z. Rocek. 2005. Development of the pelvis and posterior part of the vertebral column in the Anura. Journal of Anatomy 206:17-35.

Rosen, D. E., P. L. Forey, B. G. Gardiner, and C. Patterson. 1981. Lungfishes, Tetrapods, Paleontology, and Plesiomorphy. Bulletin of the American Museum of Natural History 167:159-276.

Sanchez, S., P. E. Ahlberg, K. M. Trinajstic, A. Mirone, and P. Tafforeau. 2012. Three-dimensional synchrotron virtual paleohistology: A new insight into the world of fossil bone microstructures. Microscopy and Microanalysis 18:1095-1105.

Schultze, H.-P. 1986. Dipnoans as sarcopterygians. Journal of Morphology 190:39-74.

Shubin, N. H. 1995. The evolution of paired fins and the origin of tetrapod limbs; pp. 39-86 in Evolutionary Biology, Springer. Boston.

Shubin, N. H., and P. Alberch. 1986. A morphogenetic approach to the origin and basic organization of the tetrapod limb. Evolutionary Biology 20:319-387.

Smith, J. L. B. 1939. A Living Fish of Mesozoic Type. Nature 143:455-456.

Stensiö, E. A. 1932. Triassic Fishes from East Greenland: Collected by the Danish Expeditions in 19291931. Meddelelser Om Greenland 83:1-305.

Stewart, T. A., J. B. Lemberg, N. K. Taft, I. Yoo, E. B. Daeschler, and N. H. Shubin. 2019. Fin ray patterns at the fin-to-limb transition. Proceedings of the National Academy of Sciences 1-9.

Taki, Y., H. Kohno, and S. Hara. 1986. Early Development of Fin-supports and Fin-rays in the Milkfish Chanos chanos. Japanese Journal of Ichthyology 32:413-420.

Yamanoue, Y., D. H. E. Setiamarga, and K. Matsuura. 2010. Pelvic fins in teleosts: Structure, function and evolution. Journal of Fish Biology 77:1173-1208.

Zhu, M., and X. Yu. 2009. Stem sarcopterygians have primitive polybasal fin articulation. Biology Letters 5:372-375.

Ziermann, J. M., R. Freitas, and R. Diogo. 2017. Muscle development in the shark Scyliorhinus canicula: Implications for the evolution of the gnathostome head and paired appendage musculature.

Frontiers in Zoology 14:1-17. 

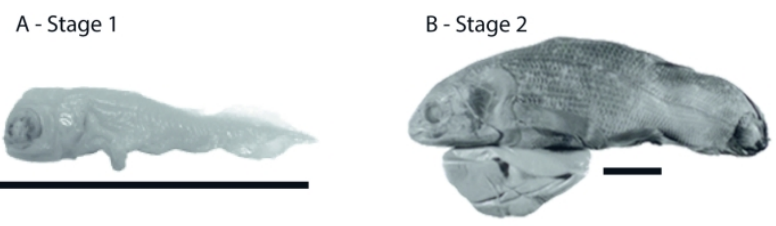

C - Stage 3
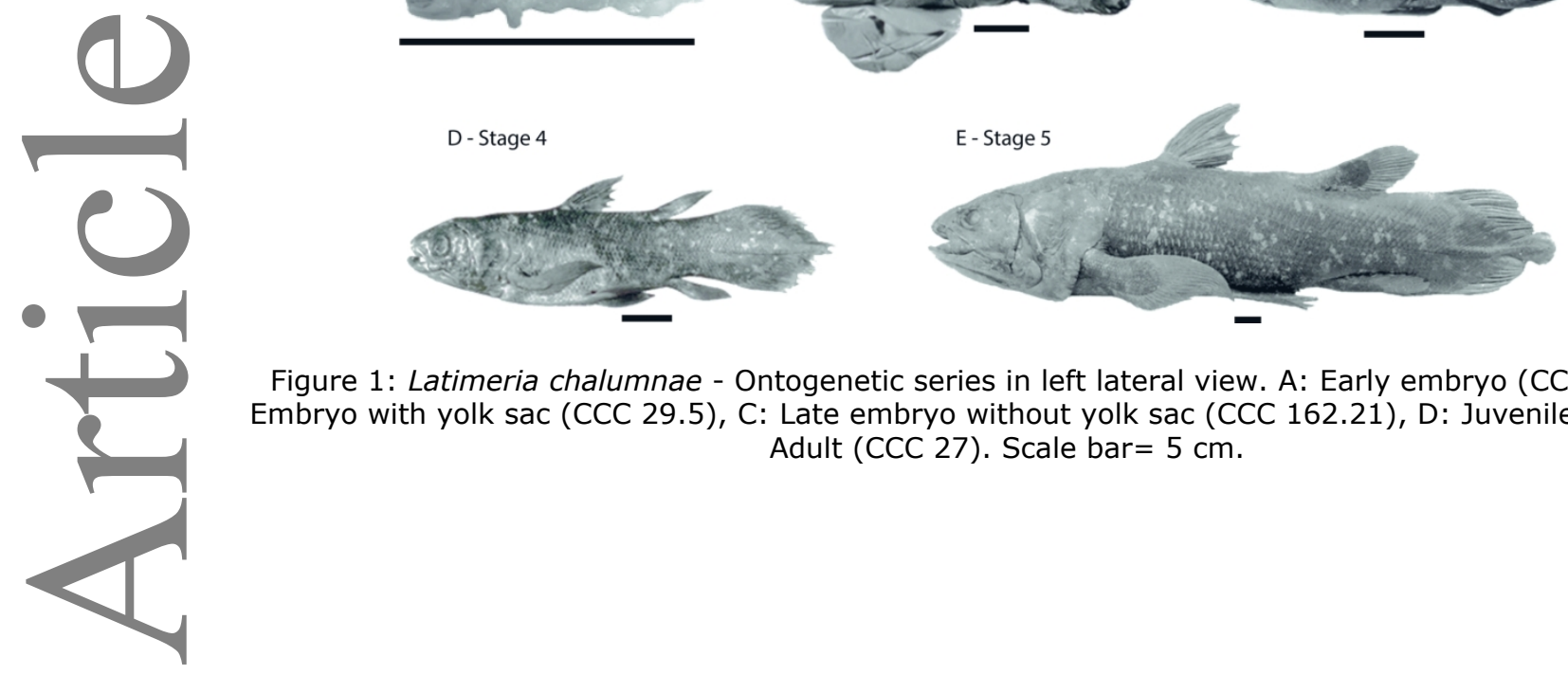

Figure 1: Latimeria chalumnae - Ontogenetic series in left lateral view. A: Early embryo (CCC 202.1), B: Embryo with yolk sac (CCC 29.5), C: Late embryo without yolk sac (CCC 162.21), D: Juvenile (CCC 94), E: Adult (CCC 27). Scale bar $=5 \mathrm{~cm}$.

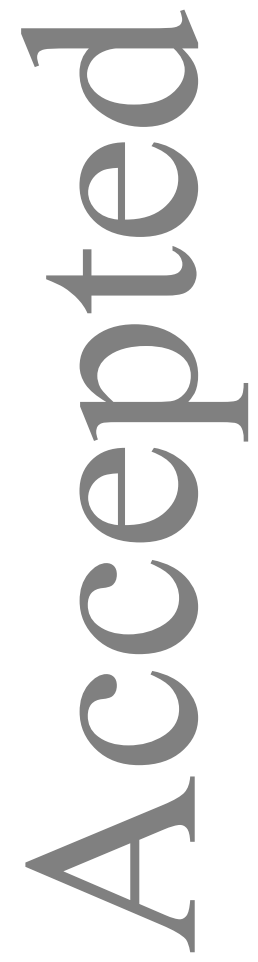



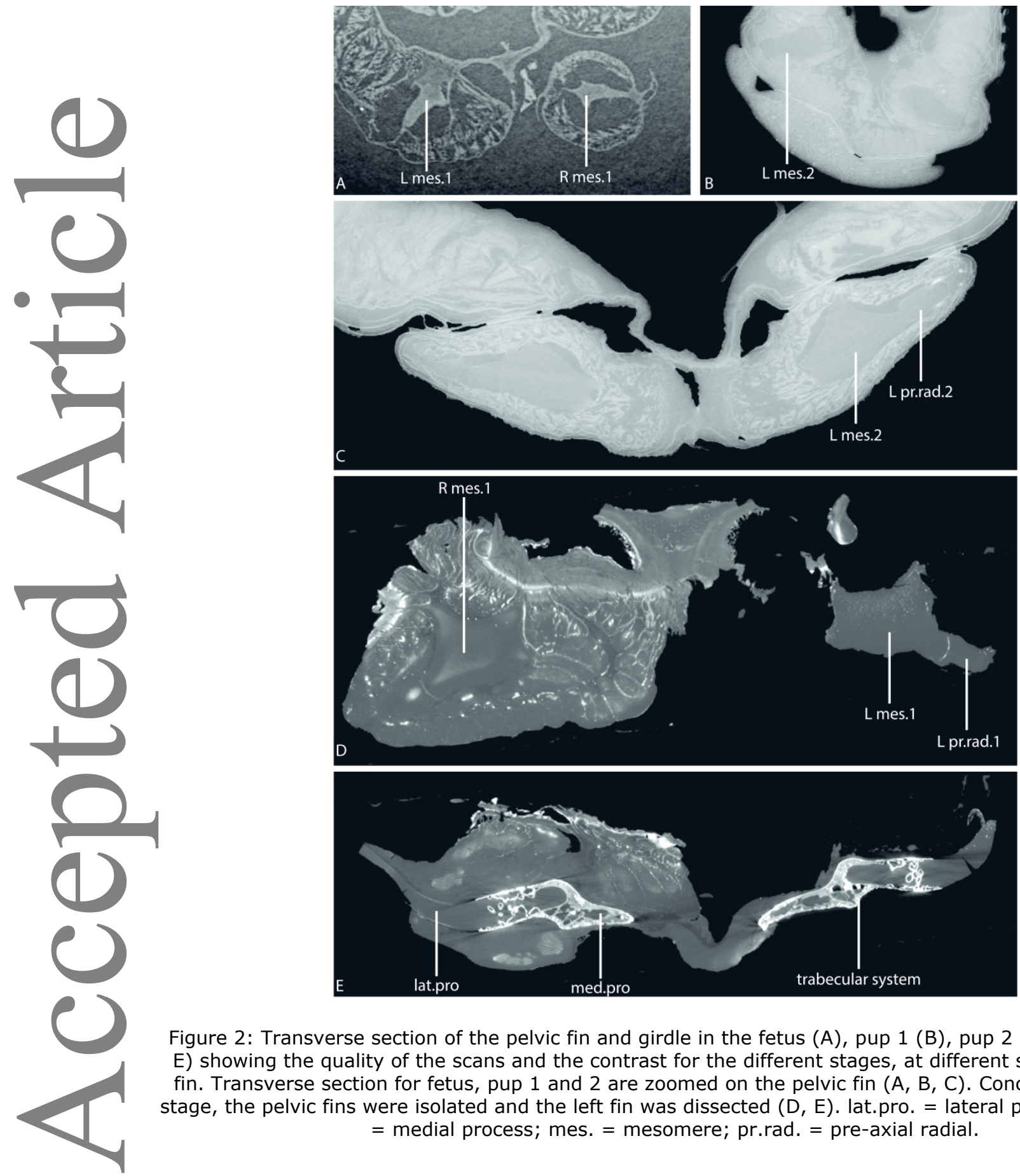

Figure 2: Transverse section of the pelvic fin and girdle in the fetus (A), pup 1 (B), pup 2 (C) and adult (D, E) showing the quality of the scans and the contrast for the different stages, at different section along the fin. Transverse section for fetus, pup 1 and 2 are zoomed on the pelvic fin (A, B, C). Concerning the adult stage, the pelvic fins were isolated and the left fin was dissected $(D, E)$. lat.pro. = lateral process; med.pro. $=$ medial process; mes. $=$ mesomere; pr.rad. $=$ pre-axial radial. 


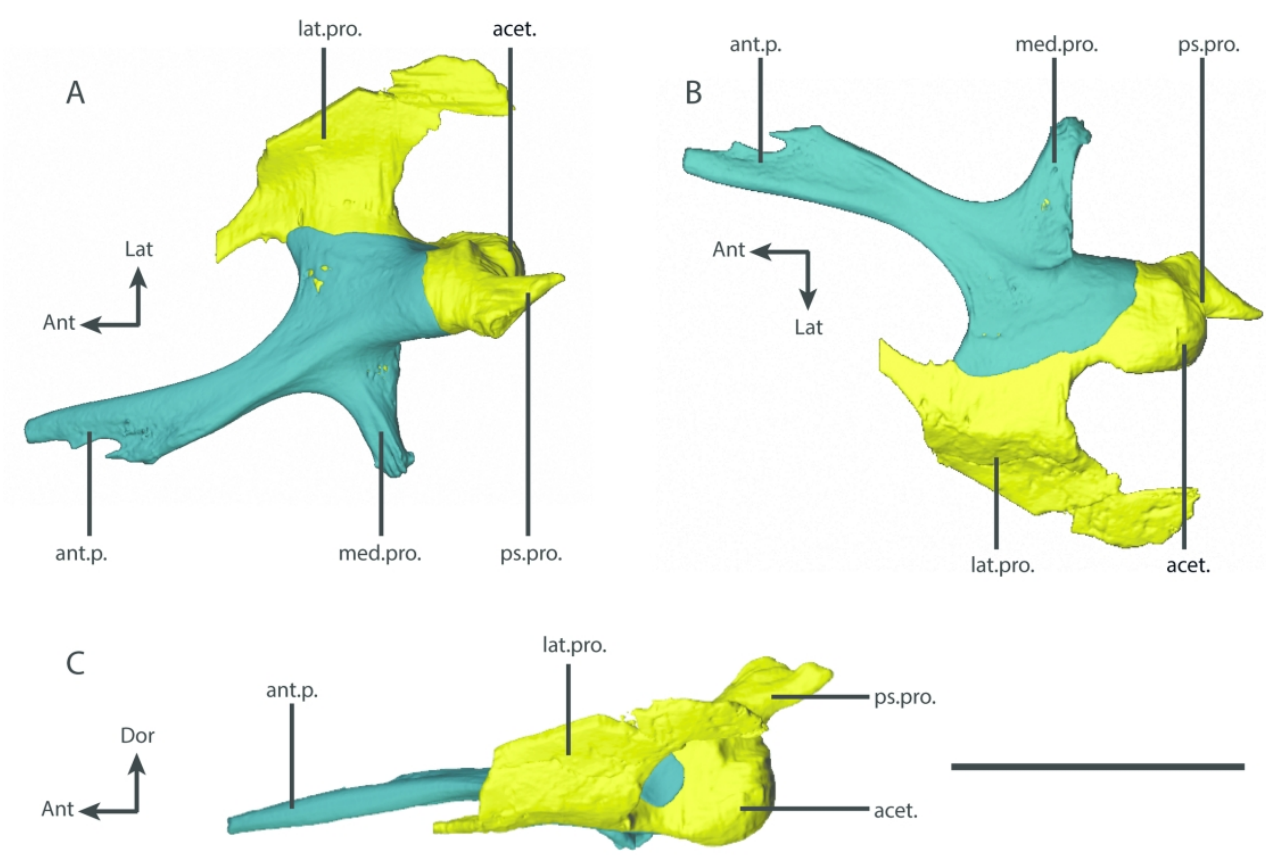

Figure 3: Latimeria chalumnae - Adult stage. Right pelvic girdle in dorsal view (A), ventral (B) and lateral view (C). act. = acetabulum; ant.p. = anterior process; lat.p. = lateral process; med.pro. = medial process; pos.p. = posterior part; ps.pro. = postero-superior process. Blue = dense part of the girdle; yellow = endoskeletal pelvic girdle. Scale bar $=50 \mathrm{~mm}$. 

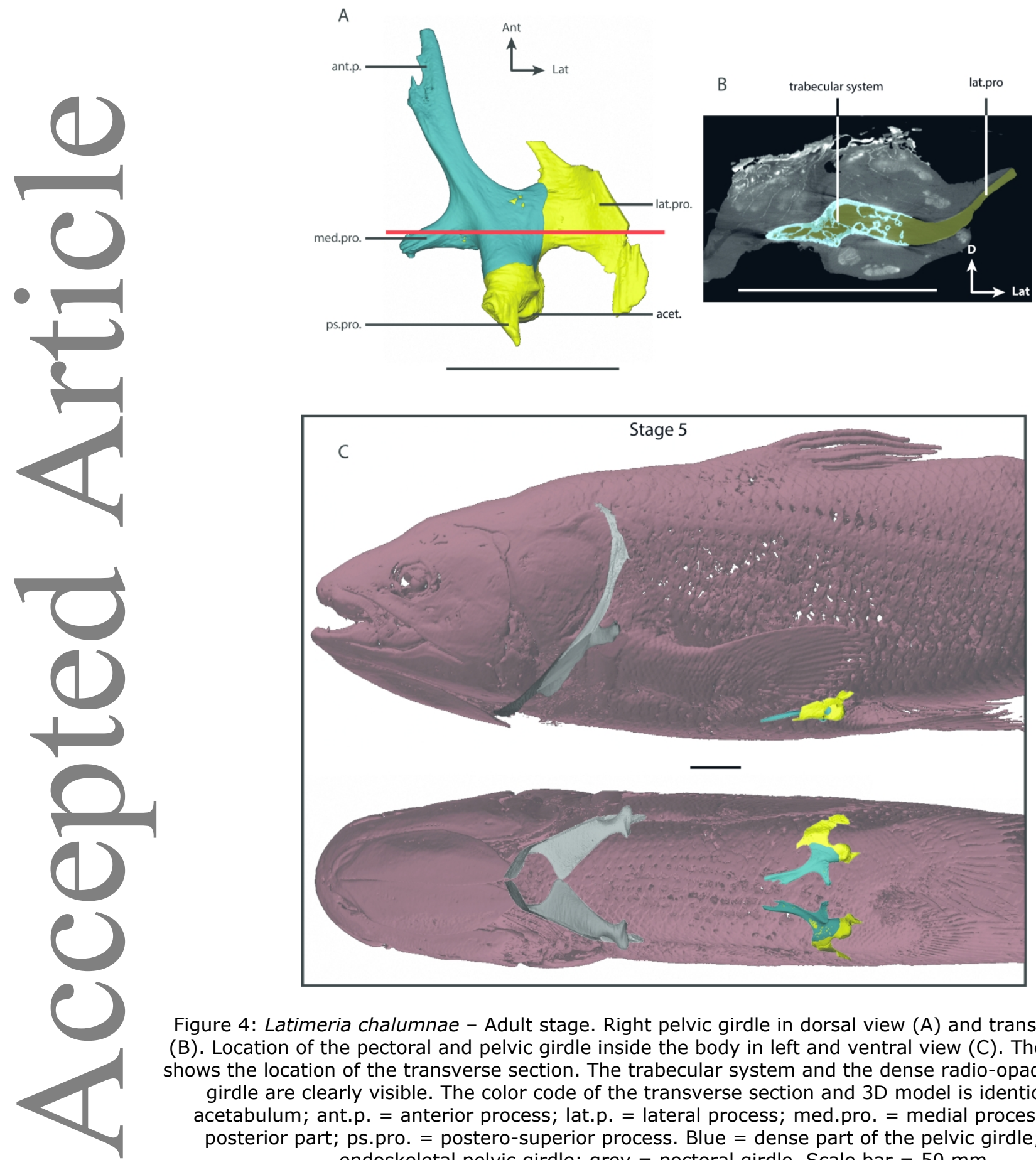

Figure 4: Latimeria chalumnae - Adult stage. Right pelvic girdle in dorsal view (A) and transverse section (B). Location of the pectoral and pelvic girdle inside the body in left and ventral view (C). The red line in $A$ shows the location of the transverse section. The trabecular system and the dense radio-opaque part of the girdle are clearly visible. The color code of the transverse section and 3D model is identical. act. = acetabulum; ant.p. = anterior process; lat.p. = lateral process; med.pro. = medial process; pos.p. = posterior part; ps.pro. = postero-superior process. Blue $=$ dense part of the pelvic girdle; yellow = endoskeletal pelvic girdle; grey $=$ pectoral girdle. Scale bar $=50 \mathrm{~mm}$. 
A
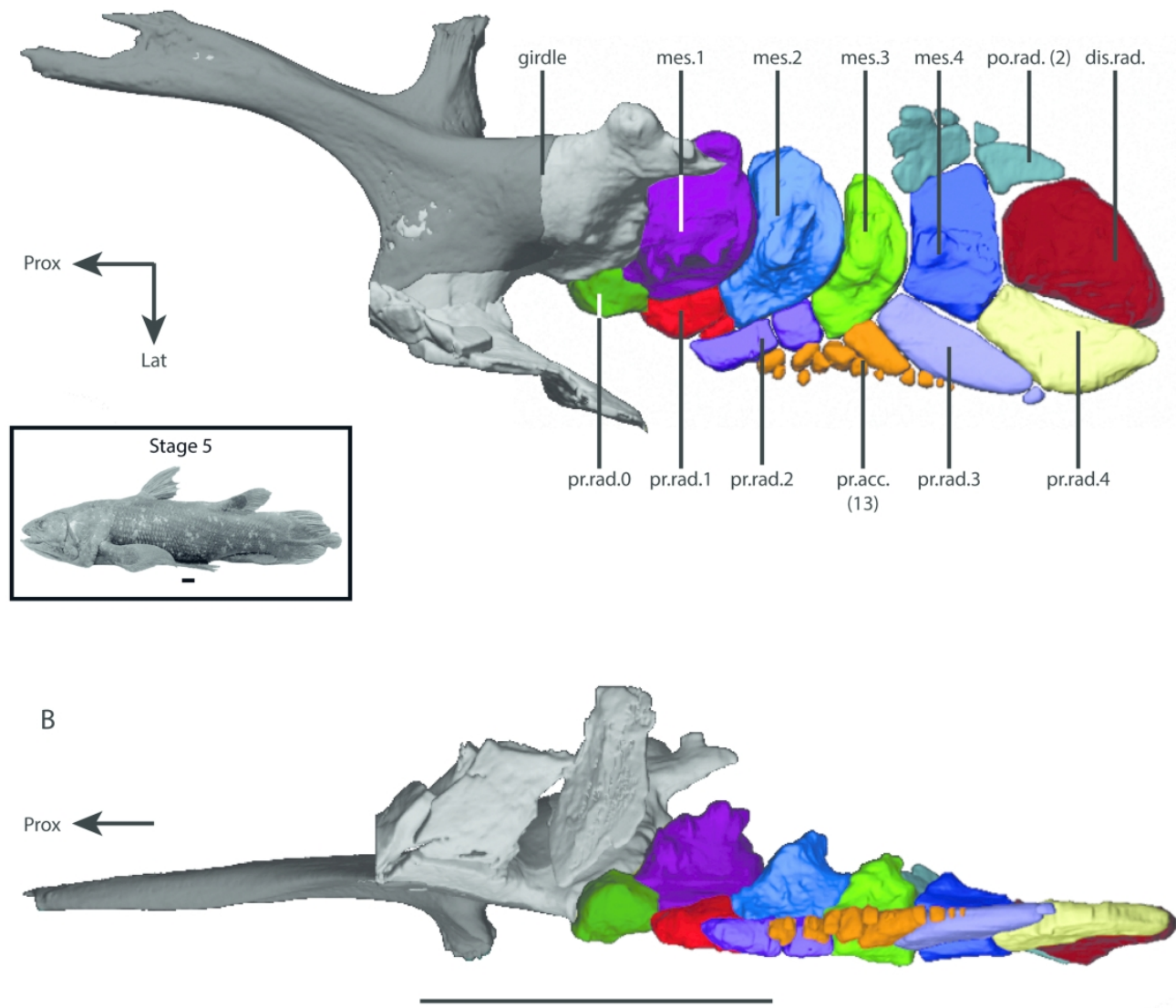

Figure 6: Latimeria chalumnae - Adult stage. Left pelvic fin in dorsal (A) and lateral (B) view. The lateral process of the girdle is broken. mes. = mesomere; po.rad. = post-axial radial; pr.acc. = pre-axial accessory elements; pr.rad. = pre-axial radial. Scale bar $=50 \mathrm{~mm}$. 
A
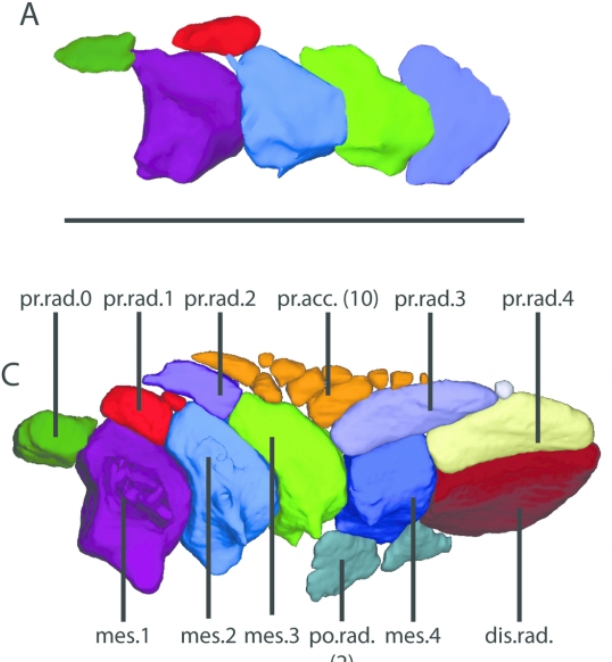

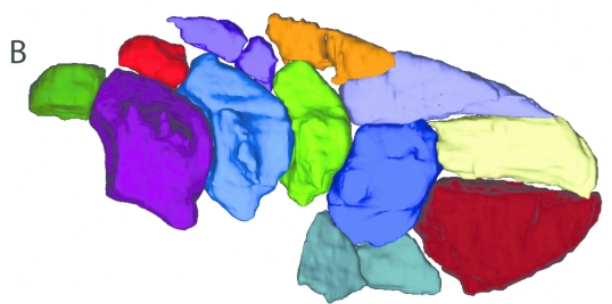

D

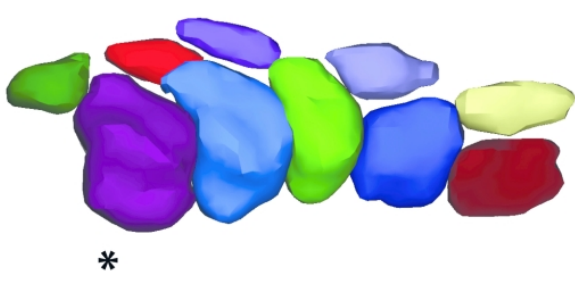

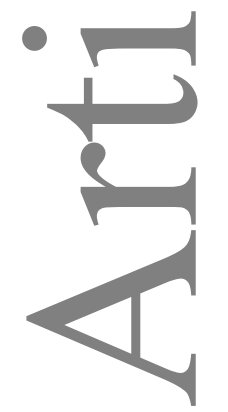
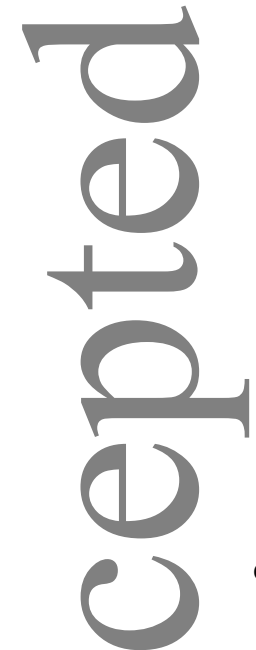

( )

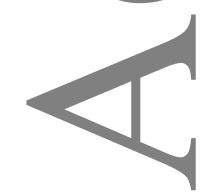

$\mathrm{E}$

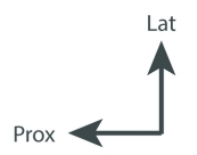

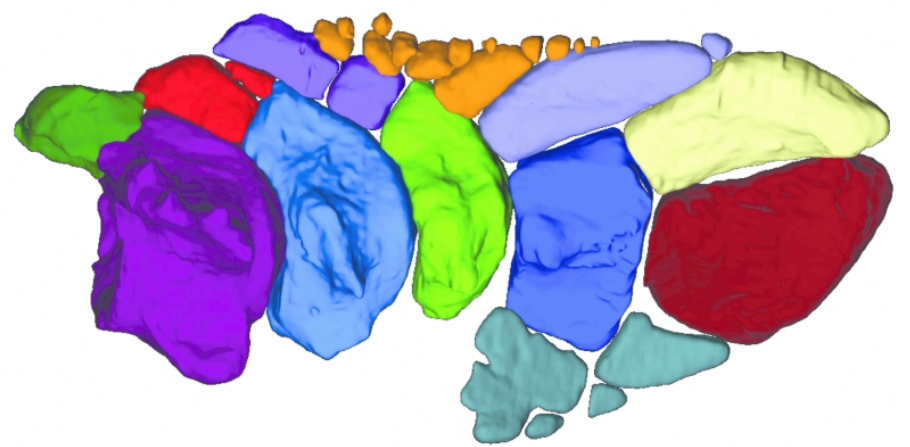

Figure 8: Latimeria chalumnae. Right (A-D) and left ( $E$ - mirror) pelvic fin of five different stages in dorsal view. A: fetus, B: pup 1, C: pup 2, D: juvenile, E: adult. *: The juvenile was scanned using MRI at low resolution which did not allow the segmentation of the smallest elements (po.rad., pr.acc.). Corresponding elements of the fin are indicated in the same color. mes. = mesomere; po.rad. = post-axial radial; pr.acc. = pre-axial accessory elements; pr.rad. = pre-axial radial. A: Scale $2 \mathrm{~mm}$; B-E: Scale bar $=10 \mathrm{~mm}$. 
A

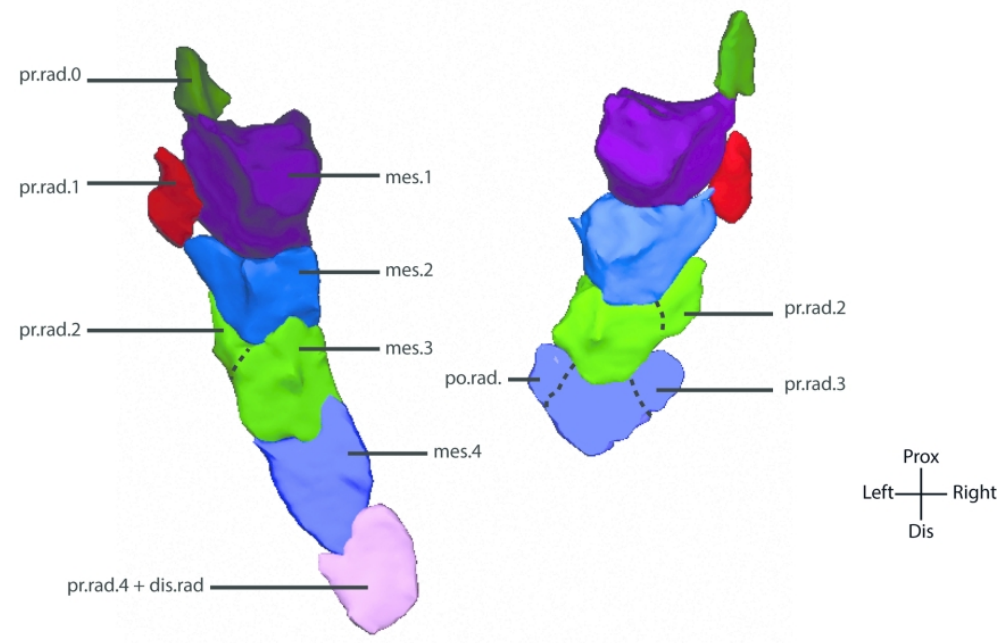

\section{B}
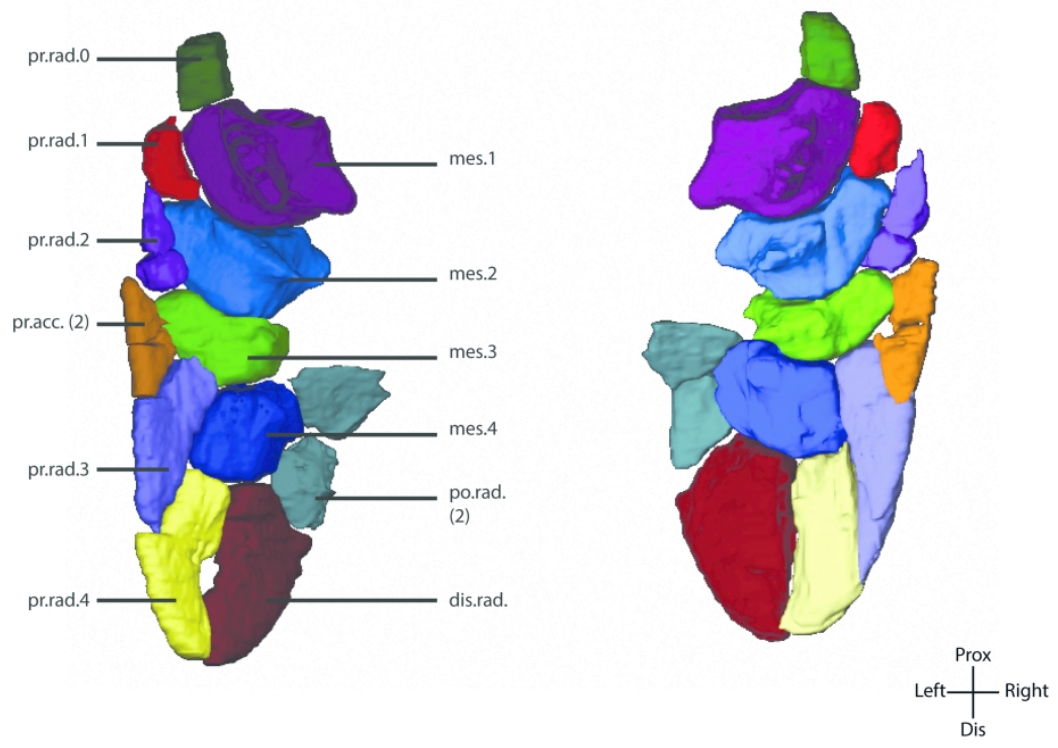

Figure 10: Latimeria chalumnae - Fetus (A) and pup 1 (B) stages. Right and left pelvic fins in dorsal. Dotted lines show the supposed splitting zone between the mesomere and the pre-axial and post-axial elements. (B) There is an asymmetry between the right and left fin in the pup 1 stage, on the distal part of the fin. mes. $=$ mesomere; po.rad. $=$ post-axial radial; pr.acc. $=$ pre-axial accessory elements; pr.rad. $=$ pre-axial radial. Not to scale. 